\title{
Pulmonary prophylactic impact of melatonin and/or quercetin: A novel therapy for inflammatory hypoxic stress in rats
}

\author{
NOUF M. AL-RASHEED \\ LAILA FADDA ${ }^{1}$ \\ HALA A. ATTIA \\ IMAN A. SHARAF $23,3 *$ \\ AZZA M. MOHAMED ${ }^{2,4}$ \\ NAWAL M. AL-RASHEED ${ }^{1}$ \\ ${ }^{1}$ Department of Pharmacology \\ King Saud University, Riyadh \\ Saudi Arabia \\ 2 Biochemistry Department \\ Faculty of Science, Al Faisaliah \\ King Abdulaziz University, Jeddah \\ Saudi Arabia \\ ${ }^{3}$ Biochemistry Department \\ Medical Research Institute \\ Alexandria University, Egypt \\ ${ }^{4}$ Therapeutic Chemistry Department \\ National Research Center, Dokki, Egypt \\ Accepted December 14, 2016 \\ Published online December 15, 2016
}

\begin{abstract}
The study aims to compare, through histological and biochemical studies, the effects of quercetin, melatonin and their combination in regulation of immuno-inflammatory mediators and heat shock protein expressions in sodium nitrite induced hypoxia in rat lungs. The results revealed that $\mathrm{NaNO}_{2}$ injection caused a significant decrease in $\mathrm{Hb}$ in rats, while serum levels of TNF- $\alpha$, IL- 6 and CRP, VEGF and HSP70 were elevated compared to the control group. Administration of melatonin, quercetin or their combination before $\mathrm{NaNO}_{2}$ injection markedly reduced these parameters. Histopathological examination of the lung tissue supported these biochemical findings. The study suggests that melatonin and/or quercetin are responsible for lung tissue protection in hypoxia by downregulation of immuno-inflammatory mediators and heat shock protein expressions. Pre-treatment of hypoxic animals with a combination of melatonin and quercetin was effective in modulating most of the studied parameters to near-normal levels.
\end{abstract}

Keywords: hypoxia, melatonin, quercetin, inflammatory mediators, heat shock protein

Exposure to hypoxia favors the increase of reactive oxygen species and modifies the levels of antioxidant substances, causing pulmonary oxidative damage, as well as establishing an inflammatory process (1). Imbalance of the redox state in lungs induced by hypoxia has been suggested to be a participant in the changes observed in lung function $(1,2)$. Hypoxia has an important role in triggering the vascular endothelial growth factor (VEGF), which is a signal protein produced by alveolar macrophages and other cell types. This factor stimulates vasculogenesis and angiogenesis to restore oxygen supply to tissues during hypoxia (3). However, VEGF has a deleterious role in pulmonary edema formation by increasing vascular permeability during hypoxia (4).

Oxygen homeostasis is maintained through a family of hypoxia-inducible transcription factors (HIFs), composed of a constitutively expressed HIF- $1 \beta$ subunit and a HIF- $\alpha$

\footnotetext{
*Correspondence; e-mail: azzamohamed99@yahoo.com
} 
subunit (HIF-1 $\alpha$ and HIF-2 $\alpha$ ) that is tightly regulated by tissue oxygen levels (4). Abnormal activation or deregulation of hypoxia-induced transcriptional pathways may contribute to the pathogenesis of various conditions. Hypoxia, via the transcription factor, hypoxia-inducible factor HIF- $1 \alpha$, induces a large number of genes encoding proteins, which participate in inflammation (5). A cross-talk between hypoxic and non-hypoxic signaling pathways, including pro-inflammatory cytokines, such as tumor necrosis factor- $\alpha$ and interleukin-1 $\beta$, may further amplify inflammatory responses by activating HIF as well as other oxygen-sensitive transcription factors, for example, nuclear factor- $\kappa \mathrm{B}(\mathrm{NF}-\kappa \mathrm{B})(6)$. Expression of heat shock proteins (HSPs) is another mechanism involved in inflammatory reactions during hypoxia. Heat shock proteins (HSPs) are a group of stress intracellular proteins whose expression increases in response to hypoxic stress which function as cytoprotectants by inhibiting various inflammatory mediators (7). However, cell damage may evoke an early release of these proteins outside the cell (8). Extracellular HSP acts as a danger signal to innate immunity and can be recognized by antigen presenting cells (APC) and their interaction subsequently triggers APC to produce the proinflammatory cytokines and activate the nuclear factor (NF)- $\kappa \mathrm{B}$, thus initiating the adaptive immune response and the presentation of antigens to the cytotoxic T cells (9). Thus, agents with the ability to suppress the expression of inflammatory molecules may be beneficial in reducing the risk of tissue injury and organ dysfunction during hypoxia.

Melatonin ( $N$-acetyl-5-methoxytryptamine), which is secreted in the circulation from the pineal gland, is produced in small amounts in the retina, the gastrointestinal system and by leukocytes. It has protective effects against cellular injuries through its potent antioxidant and anti-inflammatory properties at both physiological and pharmacological concentrations (10). Melatonin possesses anti-angiogenic activity by inhibiting stabilization of HIF-1 $\alpha$ in HCT 116 cell lines (11). Also, it has been shown that melatonin could invert the upregulation in HSP70 gene expression in human epidermis exposed to ultraviolet radiation (12).

Quercetin is a flavonoid present in many vegetables, fruits, and beverages; it possesses a broad range of pharmacological properties, including anti-inflammatory, antiproliferative and anti-oxidative (13). A previous study demonstrated that quercetin can elicit protective effects in different lung injury models $(14,31)$. At the molecular level, quercetin inhibits pulmonary oxidant stress in lung epithelial cells through inducing heme oxygenase-1 (HO-1) and via modulating the expression of antioxidant genes (14).

Although both melatonin and quercetin show different pharmacological mechanisms in modulating several pathological conditions, their modulating mechanisms for the expression of different types of inflammatory proteins causing lung tissue damage during hypoxia, particularly when used in combination, are still unclear. The present study aims to explore the effects of quercetin, melatonin or their combination in regulation of inflammatory protein expressions including VEGF, immuno-inflammatory mediators and HSP70 in hypoxic lung induced by sodium nitrite in rats.

\section{EXPERIMENTAL}

\section{Chemicals}

All chemicals used in the study were of high analytical grade, products of Sigma-Aldrich (USA) and Merck (Germany). 


\section{Animals and treatments}

Fifty adult male Wistar albino rats weighing 170-200 g were used in the study. Rats were obtained from the Experimental Animal House, Faculty of Pharmacy, King Saud University, Saudi Arabia. Animals were housed in special clean cages and maintained under standard conditions (12-h light/dark cycle, temperature $20-22{ }^{\circ} \mathrm{C}$ and $60 \%$ humidity). For acclimatization, rats were fed the standard rat pellet chow with free access to tap water $a d$ libitum for one week before the experiment. The animal experimental protocol was approved by the Experimental Animal Ethics Committee of the King Saud University, Faculty of Pharmacy (Riyadh, Saudi Arabia). After one week of acclimatization, the rats were randomly divided into five groups of ten rats each. Group 1 served as the control, group $2-\mathrm{NaNO}_{2}-$ treated animals, group $3-\mathrm{NaNO}_{2}$-treated animals injected with melatonin $\left(200 \mathrm{mg} \mathrm{kg}^{-1}\right.$, i.p.), group $4-\mathrm{NaNO}_{2}$-treated animals injected with quercetin $\left(200 \mathrm{mg} \mathrm{kg}^{-1}\right.$, i.p.), group 5 - Na$\mathrm{NO}_{2}$-treated animals injected with a combination of melatonin $\left(200 \mathrm{mg} \mathrm{kg}^{-1}\right.$, i.p. $)$ and quercetin $\left(200 \mathrm{mg} \mathrm{kg}^{-1}\right.$, i.p.). $\mathrm{NaNO}_{2}\left(60 \mathrm{mg} \mathrm{kg}^{-1}\right)$ was administered as a single dose subcutaneously. Melatonin and quercetin were administered 24 hours before $\mathrm{NaNO}_{2}$ injection. One hour after $\mathrm{NaNO}_{2}$ injection, the rats were sacrificed under ether anesthesia; blood samples were collected and divided into two parts. One part was collected into tubes containing heparin for hemoglobin determination. The other part was allowed to coagulate and was centrifuged for serum separation and used for serum biochemical analysis. After blood collection, the lungs were removed and placed in phosphate-buffered $10 \%$ formalin overnight for fixation and histopathological examination.

\section{Determination of $\mathrm{Hb}$}

$\mathrm{Hb}$ was determined colorimetrically using Drabkin's reagent according to the method after Kjeldsberg (15).

\section{Biochemical serum analyses}

Interleukin-6 (IL-6) was measured using a highly sensitive rat enzyme-linked immunosorbent assay (ELISA) kit (IBL International GmbH, Germany) following the manufacturer's instructions. Tumor necrosis factor- $\alpha$ (TNF- $\alpha$ ) was measured using the ELISA assay kit following instructions supplied by the manufacturer (DuoSet kits, R\&D Systems, USA). C-reactive protein (CRP) was estimated using the immunonephelometric assay (Dade Behring N Latex High Sensitivity CRPTM mono assay) on a Behring Nephelometer II analyzer (Dade Behring Diagnostics Inc., USA). The level of VEGF was assayed by colorimetric, quantitative, sandwich ELISA (R\&D Systems, UK) at $492 \mathrm{~nm}$, following the manufacturer's instructions. A sandwich rat HSP70 ELISA kit was used for quantitative determination of HSP70 (Kamiya Biomedical, USA).

\section{Histopathological examination}

Small pieces of the lung were fixed in $10 \%$ buffered formalin at $4{ }^{\circ} \mathrm{C}$ for 24 hours and processed to prepare $5-\mu \mathrm{m}$ thick paraffin sections. These sections were stained with hematoxylin and eosin (H\&E) to detect pathological changes due to hypoxia and the effect of certain drugs on these changes. 


\section{Statistical analysis}

Data were analyzed by comparing the values for different treatment groups with the values of individual controls. Results were expressed as mean \pm SD. Significant differences among the values were analyzed using the one-way analysis of variance (ANOVA) followed by Bonferroni's test post-ANOVA.

\section{RESULTS AND DISCUSSION}

Fig. 1 shows the effect of melatonin and/or quercetin on blood $\mathrm{Hb}$ concentration in the control and $\mathrm{NaNO}_{2}$-induced hypoxia in experimental groups. In line with previous studies (16), the present work demonstrated that induction of hypoxia in rats by $\mathrm{NaNO}_{2}$ caused a decrease in blood $\mathrm{Hb}$ level (57.9\%) compared to normal animals ( $p \leq 0.001)$. This result may indicate the development of anemia in rats in response to hypoxia. The decrease in $\mathrm{Hb}$ level may be attributed to a decrease in the red blood cell count in response to $\mathrm{NaNO}_{2}$. A previous preliminary study reported a significantly reduced red blood cell count in rats exposed to $\mathrm{NaNO}_{2}$ toxicity (13). Nitrite in toxic doses has been reported to induce hemic hypoxia. The underlying mechanism of such effect is mainly due to increased methemoglobin formation (17). Some authors have reported that $\mathrm{NaNO}_{2}$ can induce oxidative damage through free radical generation, which stimulates the oxidation of ferrous ions in oxyhemoglobin to form methemoglobin and erythrocyte lysis (18). We have found that administration of melatonin and/or quercetin to hypoxic rats significantly ameliorated the reduced level of blood $\mathrm{Hb}$ compared to hypoxic untreated animals $(p \leq 0.001)$. In comparison with the control, the changes were $23.6,14.3$ and $13.2 \%$, respectively. RBCs are highly exposed to oxygen and can be a site for radical formation under pathological conditions, resulting in their destruction. In this study, the administration of melatonin alone showed significant

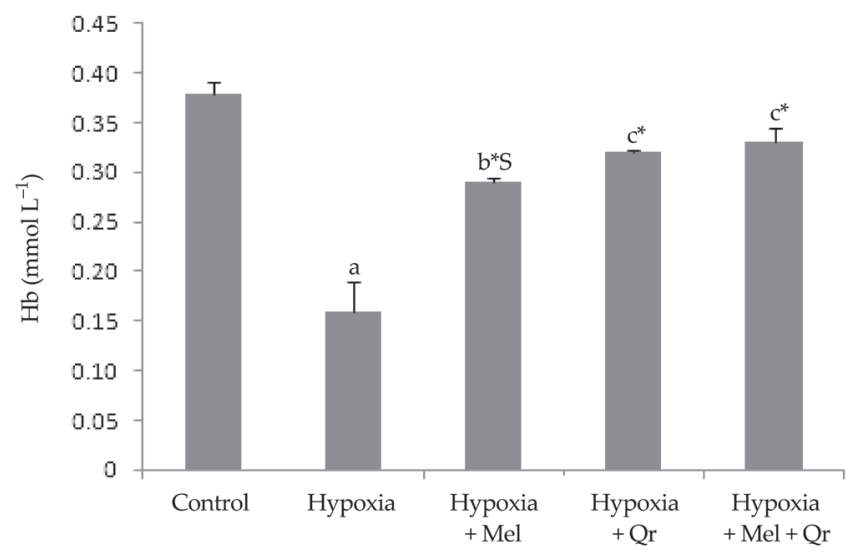

Fig. 1. Effect of melatonin (Mel) and/or quercetin (Qr) on blood hemoglobin $(\mathrm{Hb})$ in the control and hypoxia treated groups. Data are expressed as mean \pm SD $(n=10)$. Significant difference compared to the control group: ${ }^{a} p \leq 0.001,{ }^{b} p \leq 0.01,{ }^{c} p \leq 0.05$; compared to the hypoxia group: ${ }^{*} p \leq 0.001$, compared to the combination group (hypoxia $+\mathrm{Mel}+\mathrm{Qr}$ ): ${ }^{\$} p \leq 0.05$, using ANOVA, followed by Bonferroni as a post-ANOVA test. 
improvement in the $\mathrm{Hb}$ levels compared to hypoxic untreated rats $(p \leq 0.001)$, which is in agreement with a previous study that reported that melatonin leads to a significant increase in the hemoglobin level and erythrocyte count in healthy humans (19). Melatonin is actively taken up into erythrocytes under oxidative stress and is consumed in the defense of the cell, delaying $\mathrm{Hb}$ denaturation and release of hemin (20). Also, the protective effect of quercetin may rely on its antioxidant and anti-inflammatory properties. A previous study reported that quercetin could prevent the decrease in nuclear translocation of Nrf2, a key regulator of the antioxidant response, and the increase in reactive oxygen species levels by inhibiting enhancement of NADPH oxidase and xanthine oxidase activities (21).

Among the genes regulated via the HIF-1 $\alpha$ pathway under hypoxic conditions are the highly conserved HSPs, which act as cellular chaperones for proteins misfolded by cellular stress (22). In this study, HSP70 was significantly higher in the hypoxia induced group compared to the control (Fig. $2, p \leq 0.001$ ) with a percentage change of $83.1 \%$. This finding was in agreement with the recent study of Tsuchida et al. (23), who suggested that under hypoxia the HIF- $1 \alpha$-induced HSP70 overexpression in chondrocytes enhanced the metabolic activity of chondrocytes and chondroprotective effects.

Administration of melatonin and/or quercetin before $\mathrm{NaNO}_{2}$ injection markedly reduced the dramatic increase in HSP70 levels compared to $\mathrm{NaNO}_{2}$ untreated animals $(p \leq$ 0.001). Percentage changes from normal were 20.8, 22.6 and $9.4 \%$, respectively. Pretreatment of $\mathrm{NaNO}_{2}$ hypoxic animals with the combination of melatonin and quercetin was more effective in modulating most of the studied parameters to near-normal levels than each agent individually. Moreover, it has been reported that melatonin effectively prevented acidification of cytosol, causing significant downregulation of HSP70 in melatoninincubated skin samples (24).

In line with the previous study (3), the vascular endothelial growth factor (VEGF) was significantly increased after hypoxia (32.9\% change from normal) and administration of melatonin and/or quercetin ameliorated the hypoxic effect (Fig. 3, $p \leq 0.001$ ) by $8.3,8.3$ and $6.9 \%$ from normal, respectively. This may be due to the activation of HIF-1 in hypoxia,

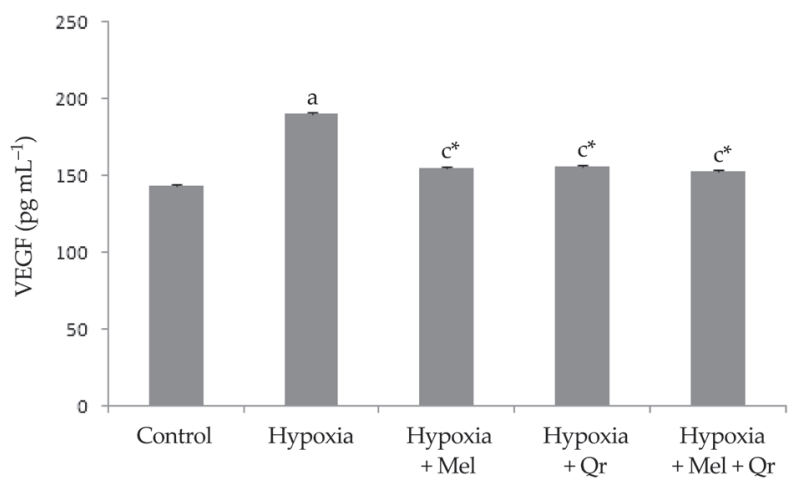

Fig. 2. Effect of melatonin (Mel) and/or quercetin (Qr) on serum VEGF in the control and hypoxia treated groups. Data are expressed as mean \pm SD $(n=10)$. Significant difference compared to the control group: ${ }^{a} p \leq 0.001,{ }^{c} p \leq 0.05$; compared to the hypoxia group: ${ }^{*} p \leq 0.001$; compared to the combination group (hypoxia $+\mathrm{Mel}+\mathrm{Qr}$ ): ${ }^{\$} p \leq 0.05$, using ANOVA, followed by Bonferroni as a postANOVA test. 
resulting in increased expression of a number of genes encoding proteins such as erythropoietin (EPO), vascular endothelial growth factor (VEGF) and inducible nitric oxide synthase (iNOS), which increase tissue oxygenation. These factors allow adaptation to hypoxia, which is directed toward increasing tissue perfusion and oxygenation and hence overcoming the initial hypoxic insult. Melatonin suppressed HIF-1 $\alpha$ transcriptional activity, leading to reduction in different angiogenic processes such as VEGF expression (20).

In the present study, quercetin inhibited hypoxia-induced VEGF, which was in accord with the study of Anso et al. (25). When cells were exposed to hypoxia in the presence of this flavonoid, HIF-1 $\alpha$ translocated to the nucleus and interacted with p300/CBP, but this complex was transcriptionally inactive. Taken together, these findings indicate that flavonoids impair VEGF transcription by an alternative mechanism that does not depend on nuclear HIF levels (26).

Furthermore, the current study revealed that rats exposed to hypoxia exhibited higher circulating levels of TNF- $\alpha$, IL-6 and CRP compared to the controls (Figs. 3, 4 and 5, resp., $p \leq 0.001$ ). Deviations in the levels of these inflammatory markers from the normal level were 74.0, 57.4 and $100.0 \%$, respectively. These results have shown that the release of pro-inflammatory cytokines, which are the systemic inflammatory markers, is associated with hypoxia (6). Parts of our findings are consistent with other reports of increased TNF$\alpha$ and IL-6 levels in rats subjected to hypoxia (6). When exposed to hypoxia, NF- $\kappa$ B is activated and stimulates increased production of circulating cytokines such as TNF- $\alpha$ and IL-6, which, in turn, activates signaling cascades to enhance NF- $\kappa$ B activation. Positive regulation contributes to the amplification of inflammatory responses (6).

Pre-injection of the studied agents, alone or in combination, to rats before induction of hypoxia, successfully attenuated hypoxia-induced stimulation of the inflammatory immunologic biomarkers, TNF- $\alpha$, IL- 6 and CRP. This beneficial impact of the two agents may be related to their beneficial anti-inflammatory and immunomodulatory actions. This result is confirmed by previous investigations, reporting that supplementation of either quercetin or melatonin could protect against the inflammatory responses caused by dif-

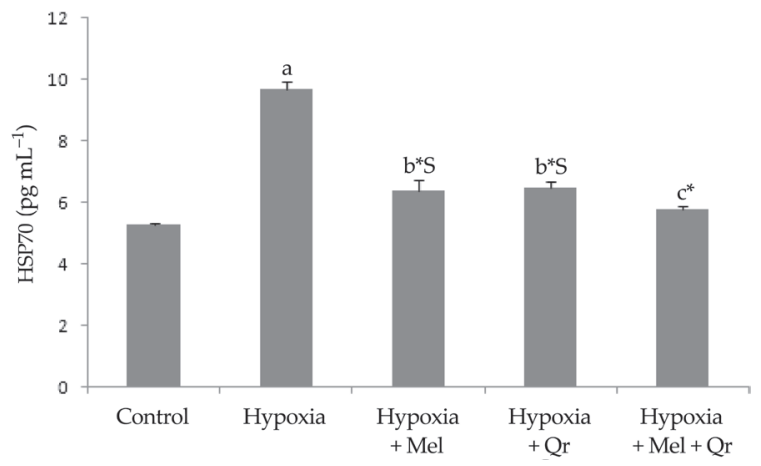

Fig. 3. Effect of melatonin (Mel) and/or quercetin (Qr) on serum HSP70 in the control and hypoxia treated groups. Data are expressed as mean $\pm \mathrm{SD}(n=10)$. Significant difference compared to the control group: ${ }^{a} p \leq 0.001,{ }^{b} p \leq 0.01,{ }^{c} p \leq 0.05$; compared to the hypoxia group: ${ }^{*} p \leq 0.001$; compared to the combination group (hypoxia $+\mathrm{Mel}+\mathrm{Qr}$ ): ${ }^{\$} p \leq 0.05$, using ANOVA, followed by Bonferroni as a post-ANOVA test. 


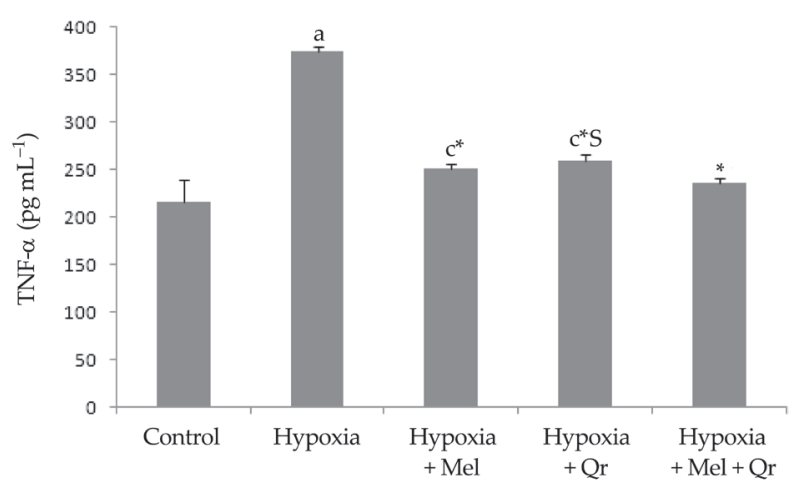

Fig. 4. Effect of melatonin (Mel) and/or quercetin (Qr) on serum TNF- $\alpha$ in the control and hypoxia treated groups. Data are expressed as mean $\pm \operatorname{SD}(n=10)$. Significant difference compared to the control group: ${ }^{a} p \leq 0.001,{ }^{c} p \leq 0.05$; compared to the hypoxia group: ${ }^{*} p \leq 0.001$; compared to the combination group (hypoxia $+\mathrm{Mel}+\mathrm{Qr}$ ): ${ }^{\$} p \leq 0.05$, using ANOVA, followed by Bonferroni as a postANOVA test.

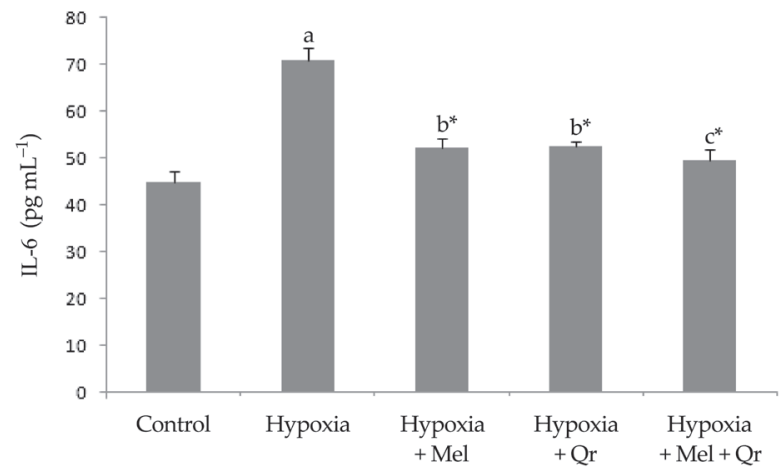

Fig. 5. Effect of melatonin (Mel) and/or quercetin (Qr) on serum IL-6 in the control and hypoxia treated groups. Data are expressed as mean \pm SD $(n=10)$. Significant difference compared to the control group: ${ }^{a} p \leq 0.001,{ }^{\mathrm{b}} p \leq 0.01,{ }^{c} p \leq 0.05$; compared to the hypoxia group: ${ }^{*} p \leq 0.001$, using ANOVA, followed by Bonferroni as a post-ANOVA test.

ferent pathological conditions through inhibition of the expression of these mediators $(4$, 13). Indeed, our results show that administration of melatonin significantly decreased the amount of inflammatory cytokines TNF- $\alpha$ and IL- 6 of the hypoxic rats $(p \leq 0.001)$. Melatonin modulates inflammation by inhibiting the NF- $\kappa$ B nuclear erythroid 2-related factor 2 (Nrf2) cascades and downstream mediators of inflammation (27). Quercetin exerts its antioxidant properties by scavenging reactive oxygen and nitrogen species. It increases endothelial nitric oxide and induces vasodilatation through smooth muscle relaxation. It has been experimentally used in the treatment of ischemia and myocarditis (28). Experimental studies have reported that quercetin protects from ischemia-reperfusion injury through prevention of apoptosis and inhibition of the mitochondria-dependent caspase pathway in animals (29). 


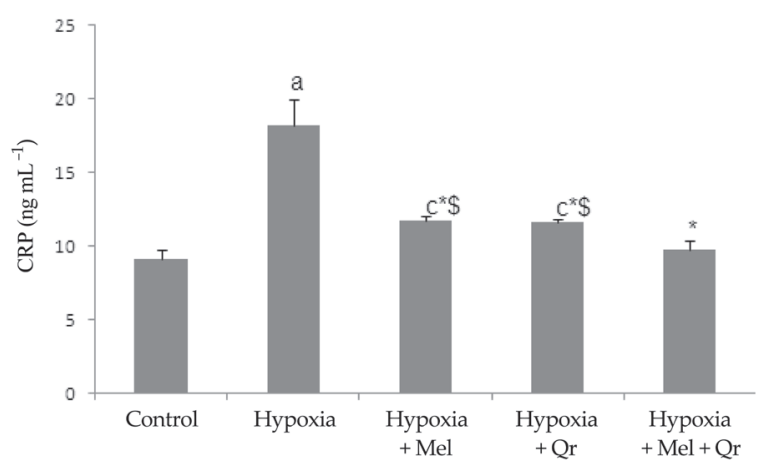

Fig. 6. Effect of melatonin (Mel) and/or quercetin (Qr) on serum CRP in the control and hypoxia treated groups. Data are expressed as mean $\pm \mathrm{SD}(n=10)$. Significant difference compared to the control group: ${ }^{a} p \leq 0.001,{ }^{c} p \leq 0.05$; compared to the hypoxia group: ${ }^{*} p \leq 0.001$; compared to the combination group (hypoxia $+\mathrm{Mel}+\mathrm{Qr}$ ): ${ }^{\$} p \leq 0.05$, using ANOVA, followed by Bonferroni as a post-ANOVA test.

a)

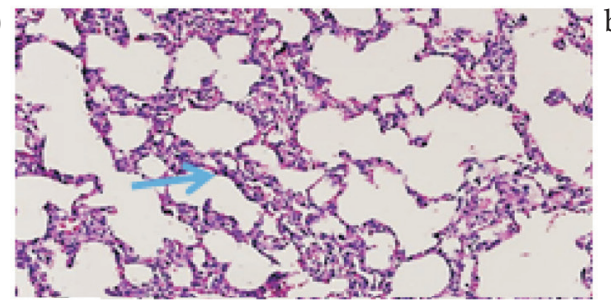

c)

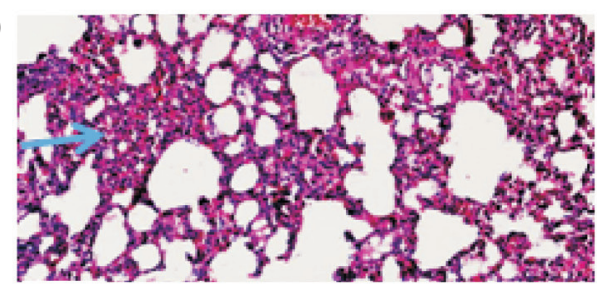

b)

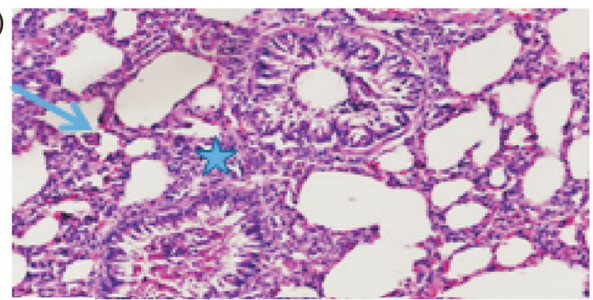

d)

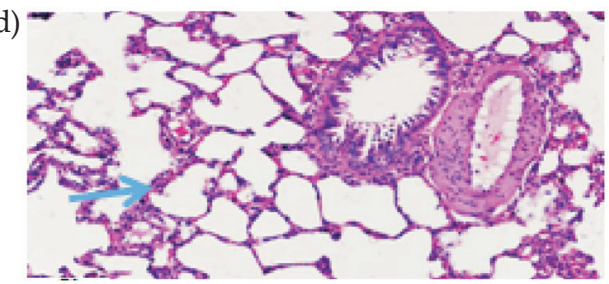

e)

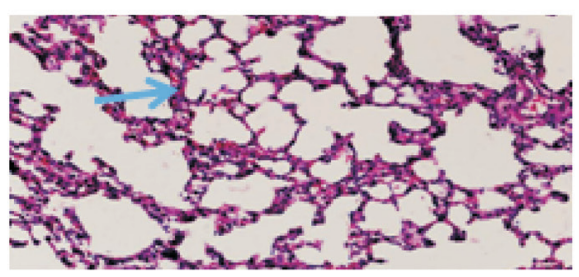

Fig. 7. Light photomicrographs of rat lung stained with hematoxylin and eosin (scale bar: $100 \mu \mathrm{m}$ ), representing: a) normal lung alveoli and septae (arrow), b) section of lung from a rat exposed to hypoxia showing marked thickening of interalveolar septa (arrow) and alveoli and foci of inflammatory cellular infiltration (star), c)-e) sections of lung from a rat exposed to hypoxia receiving melatonin, quercetin and a combination of both, respectively. 
Extensive variations were observed during the histopathological study of rat lungs. Administration of $\mathrm{NaNO}_{2}$ caused degeneration of the alveoli and thickening of interalveolar septae in addition to focal cellular infiltration (Figs. 7a-e). Similar observation was found in another study during $\mathrm{CCl}_{4}$ administration to rat lungs (30). Treatment with melatonin or quercetin showed marked improvement of the alveoli and alveolar septae and a marked decrease of cellular infiltration, especially in rats that received a combination of melatonin and quercetin. This beneficial effect of both melatonin and quercetin was previously documented in animals that underwent experimental lung damage (31). Greater improvement of pathological changes is obvious in rats that received co-treatment of both drugs. This result may predict the beneficial synergistic protective impact of the combination of melatonin and quercetin against lung damage induced by hypoxia.

\section{CONCLUSIONS}

The obtained results have proven that melatonin and/or quercetin are likely to be responsible for lung tissue protection against hypoxic lung damage in rats through their downregulation of immuno-inflammatory mediators and heat shock protein expressions. The combination of melatonin and quercetin was more effective in modulating most of the studied parameters to near-normal levels than each agent individually. Therefore, the current findings may have important implications on the development of a new therapeutic strategy aimed at manipulating melatonin and quercetin in combination as a supplement for prophylaxis from hypoxic lung injury.

Acknowledgements. - This research was supported by a grant from the Research Center of the Center for Female Scientific and Medical Colleges, Deanship of Scientific Research, King Saud University.

\section{REFERENCES}

1. N. C. Gonzalez and J. G.Wood, Alveolar hypoxia-induced systemic inflammation: what low $\mathrm{PO}_{2}$ does and does not do, Adv. Exp. Med. Biol. 662 (2010) 27-32; DOI: 10.1007/978-1-4419-1241-1_3.

2. J. T. Sylvester, L. A. Shimoda, P. I. Aronson and J. P. T. Ward, Hypoxic pulmonary vasoconstriction, Physiol. Rev. 92 (2012) 367-520; DOI: 10.1152/physrev.00041.2010.

3. M. Dai, P. Cui, M. Yu, J. Han, H. Li and R. Xiu, Melatonin modulates the expression of VEGF and HIF-1 $\alpha$ induced by $\mathrm{CoCl}_{2}$ in cultured cancer cells, J. Pineal Res. 44 (2008) 121-126; DOI: 10.1111/j.1600-079X.2007.00498.x.

4. C. Kaur, V. Sivakumar, J. Lu, F. R. Tang and E. A. Ling, Melatonin attenuates hypoxia-induced ultrastructural changes and increased vascular permeability in the developing hippocampus, Brain Pathol. 18 (2008) 533-547; DOI: 10.1111/j.1750-3639.2008.00156.x.

5. G. L. Semenza, Regulation of oxygen homeostasis by hypoxia-inducible factor 1, Physiology (Bethesda) 24 (2009) 97-106; DOI: 10.1152/physiol.00045.2008.

6. V. Nizet and R. S. Johnson, Interdependence of hypoxic and innate immune responses, Nat. Rev. Immunol. 9 (2009) 609-617; DOI: 10.1038/nri2607.

7. Z. Zheng, J. Y. Kim, H. Ma, J. E. Lee and M. A. Yenari, Anti-inflammatory effects of the $70 \mathrm{kDa}$ heat shock protein in experimental stroke, J. Cereb. Blood Flow Metab. 28 (2008) 53-63; DOI:10.1038/sj. jcbfm.9600502.

8. S. K. Calderwood, S. S. Mambula and P. J. Gray, Jr., Extracellular heat shock proteins in cell signaling and immunity, Ann. NY Acad. Sci. 1113 (2007) 28-39; DOI: 10.1196/annals.1391.019. 
9. P. Srivastava, Interaction of heat shock proteins with peptides and antigen presenting cells: chaperoning of the innate and adaptive immune responses, Annu. Rev. Immunol. 20 (2002) 395-425; DOI: 10.1146/annurev.immunol.20.100301.064801.

10. Y. Liu, T. G. Lim and L. F. Man, Melatonin attenuates intermittent hypoxia-induced lipid peroxidation and local inflammation in rat adrenal medulla, Int. J. Mol. Sci. 15 (2014) 18437-18452; DOI: 10.3390/ijms151018437.

11. S. Y. Park, W. J. Jang, E. Y. Yi, J. Y. Jang, Y. Jung, J. W. Jeong and Y. J. Kim, Melatonin suppresses tumor angiogenesis by inhibiting HIF-1 $\alpha$ stabilization under hypoxia, J. Pineal Res. 48 (2010) 178-184.

12. K. Kleszczyński, S. Zwicker, S. Tukaj, M. Kasperkiewicz, D. Zillikens, R. Wolf and T. W. Fischer, Melatonin compensates silencing of heat shock protein 70 and suppresses ultraviolet radiationinduced inflammation in human skin ex vivo and cultured keratinocytes, J. Pineal Res. 58 (2015) 117-126; DOI: 10.1111/jpi.12197.

13. S. Chirumbolo, The role of quercetin, flavonols and flavones in modulating inflammatory cell function, Inflamm. Allergy Drug Targets 9 (2010) 263-285.

14. R. Huang, T. Zhong and H. Wu, Quercetin protects against lipopolysaccharide-induced acute lung injury in rats through suppression of inflammation and oxidative stress, Arch. Med. Sci. 11 (2015) 427-432; DOI: 10.5114/aoms.2015.50975.

15. C. R. Kjeldsberg, Principles of hematologic examination, in: G. R. Lee, T. C. Bittell, J. Foerster, J. W. Athens and J. N. Lukens (Eds.), Wintrobe's Clinical Hematology, Lea \& Febiger, Philadelphia-London 1993, Vol. 1, pp. 7-37.

16. N. A. A. Aita and F. F. Mohammed, Effect of marjoram oil on the clinicopathological, cytogenetic and histopathological alterations induced by sodium nitrite toxicity in rats, Global Vet. 12 (2014) 606-616.

17. R. Linberg, C. D. Conover, K. L. Shum and R. G. Shorr, Hemoglobin based oxygen carriers: how much methemoglobin is too much?, Artif. Cells Blood Subst. Immob. Biotechnol. 26 (1998) 133-148.

18. M. M. Rahman, S. J. Kim, G. B. Kim, C. U. Hong, Y. U. Lee, S. Z. Kim, J. S. Kim and H. S. Kang, Nitrite induced methemoglobinaemia affects blood ionized and total magnesium level by hydrolysis of plasma adenosine triphosphate in rat, Basic Clin. Pharmacol. Toxicol. 105 (2009) 294-300; DOI: 10.1111/j.1742-7843.2009.00450.x.

19. S. A. Arushanian, E. B. Beier and O. A. Mastiagina, Melatonin effect on the hematological indices of healthy humans, Eksp. Klin. Farmakol. 69 (2006) 36-38.

20. R. Ozmerdivenli, K. Karacabey, C. Gundogdu and T. Sevindi, Protective role of melatonin on blood parameters following irradiation in rat, Afr. J. Biotechnol. 10 (2011) 18564-18568; DOI: 10.5897/ AJB11.1638.

21. C. Carrasco-Pozo, R. L. Castillo, C. Beltrán, A. Miranda, J. Fuentes and M. Gottel, Molecular mechanisms of gastrointestinal protection by quercetin against indomethacin-induced damage: role of NF-кB and Nrf2, J. Nutr. Biochem. 27 (2016) 289-298; DOI: 10.1016/j.jnutbio.2015.09.016.

22. N. A. Baird, D. W. Turnbull and E. A. Johnson, Induction of the heat shock pathway during hypoxia requires regulation of heat shock factor by hypoxia-inducible factor-1, J. Biol. Chem. 281 (2006) 38675-38681.

23. S. Tsuchida, Y. Arai, K. A. Takahashi, T. Kishida, R. Terauchi, K. Honjo, S. Nakagawa, H. Inoue, K. Ikoma, K. Ueshima, T. Matsuki, O. Mazda and T. Kubo, HIF-1 $\alpha$-induced HSP70 regulates anabolic responses in articular chondrocytes under hypoxic conditions, J. Orthop. Res. 32 (2014) 975980; DOI: 10.1002/jor.22623.

24. K. Kleszyński, S. Zwicker, S. Tukaj, M. Kasperkiewicz, D. Zillikens, R. Wolf and T. W. Fischer, Melatonin compensates silencing of heat shock protein 70 and suppresses ultraviolet radiationinduced inflammation in human skin ex vivo and cultured keratinocytes, J. Pineal Res. 58 (2015) 117-126; DOI: 10.1111/jpi.12197. 
25. E. Ansó, A. Zuazo, M. Irigoyen, M. C. Urdaci, A. Rouzaut and J. J. Martínez-Irujo, Flavonoids inhibit hypoxia-induced vascular endothelial growth factor expression by a HIF-1 independent mechanism, Biochem. Pharmacol. 79 (2010) 1600-1609; DOI: 10.1016/j.bcp.2010.02.004.

26. D.-H. Lee and Y. J. Lee, Quercetin suppresses hypoxia-induced accumulation of hypoxia-inducible factor-1a (HIF-1a) through inhibiting protein synthesis, J. Cell. Biochem. 105 (2008) 546-553; DOI: $10.1002 / j \mathrm{cb} .21851$.

27. G. Negi, A. Kumar and S. S. Sharma, Melatonin modulates neuroinflammation and oxidative stress in experimental diabetic neuropathy: Effects on NF- $\kappa B$ and Nrf2 cascades, J. Pineal Res. 50 (2011) 124-131; DOI: 10.1111/j.1600-079X.2010.00821.x.

28. M. Milenkovic, R. N. Arsenovic, V. Z. Stojic, B. Bufan, D. Vucicevic and I. Jancic, Quercetin ameliorates experimental autoimmune myocarditis in rat, J. Pharm. Pharm. Sci. 13 (2010) 311-319.

29. S. Arumugam, R. A. Thandavarayan, W. Arozal, F. R. Sari, V. V. Giridharan and V. Soetikno, Quercetin offers cardioprotection against progression of experimental autoimmune myocarditis by suppression of oxidative and endoplasmic reticulum stress via endothelin-1/MAPK signaling, Free Rad. Res. 46 (2012) 154-163; DOI: 10.3109/10715762.2011.647010.

30. S. A. Ganie, E. Haq, A. Hamid, Y. Qurishi, Z. Mahmood, B. A. Zargar, A. Masood and M. A. Zargar, Carbon tetrachloride induced kidney and lung tissue damages and antioxidant activities of the aqueous rhizome extract of Podophyllum hexandrum, BMC Complemen, Altern. Med. 11 (2011) Article 17; DOI: 10.1186/1472-6882-11-17.

31. E. Taslidere, M. Esrefoglu, H. Elbe, A. Cetin and B. Ates, Protective effects of melatonin and quercetin on experimental lung injury induced by carbon tetrachloride in rats, Exp. Lung Res. 40 (2014) 59-65; DOI: 10.3109/01902148.2013.866181. 